\section{EMBRYAIDDLE Aeronautical University}

SCHOLARLY COMMONS

\section{International Journal of Aviation,} Aeronautics, and Aerospace

$1-6-2015$

\title{
Risk Perception in Aviation Students: Weather Matters
}

Ric Ferraro PhD

Univ. North Dakota, f.richard.ferraro@email.und.edu

Darci VanDyke

darci.vandyke@my.und.edu

Mary Zander

mary.zander@my.und.edu

Krista Anderson

krista.anderson@my.und.edu

Bethany Kuehlen

bethany.kuehlen@my.und.edu

Follow this and additional works at: https://commons.erau.edu/ijaaa

Part of the Aviation Safety and Security Commons, Other Social and Behavioral Sciences Commons, and the Psychology Commons

\section{Scholarly Commons Citation}

Ferraro, R., VanDyke, D., Zander, M., Anderson, K., \& Kuehlen, B. (2015). Risk Perception in Aviation Students: Weather Matters. International Journal of Aviation, Aeronautics, and Aerospace, 2(1). https://doi.org/10.15394/ijaaa.2015.1044

This Article is brought to you for free and open access by the Journals at Scholarly Commons. It has been accepted for inclusion in International Journal of Aviation, Aeronautics, and Aerospace by an authorized administrator of Scholarly Commons. For more information, please contact commons@erau.edu. 
Green (2001) reported that although aviation is considered a high-risk activity, a full third of the flight instructors she interviewed for her study said that flying is not a risky activity. The relevance of this apparent disconnect between reality and perception of risk in flight instructors relates to instructional choice and strategies that instructors impart on their students. As Green (2001) suggests, pilot attitude about risk is developed early in flight training and that adequate training of what constitutes a risky situation is critical for successful training. Thus, adequate risk perception in students training to become pilots is essential and should occur as early in training as possible. The current study tested aviation students in training and compared their risk perception performance to non-aviation students.

While Green's (2001) relates to the present paper, risky decision-making has been a topic of interest within psychology and aviation for many years (Hunter, 2002; Slovic \& Lichtenstein, 1968; Tversky \& Kahneman, 1981). Much risky decision-making often involves some aspect of uncertainty or some unknown aspect of the situation at hand. From an aviation perspective, many situations would be deemed risky even when performed by seasoned veterans and socalled experts (You, Ji, \& Han, 2013). Exposure to risky situations and risky decision-making can often impact pilots negatively (Hunter, 2006). Hunter (2006) found that pilots who had been exposed to a more hazardous aviation event would then rate it lower in overall risk and, in turn, be more likely to rate general aviation safety more inaccurately.

Pilot error in decision-making is often identified as the key factor in aviation accidents, and it is often the case that aviation brings with it situations that are often potentially challenging (Burian, Barshi, \& Dismukes, 2006). Risk perception may be defined as "the recognition of the risk inherent in a situation" (Hunter, 2002, p. 3) and is influenced by both the situation and individual characteristics, such as locus of control (You et al., 2013).

For pilots, weather represents an important area for risk perception. A variety of personal (e.g. optimism) and situation (e.g. flight time and flight length) factors have been noted in influencing pilots' decisions to fly in adverse weather (Goh \& Wiegmann, 2001). Research has shown that aviation accidents resulting from flying in deteriorating weather are more likely for less experienced pilots (Goh \& Wiegmann, 2002). How one interprets the risk of weather-related information is also of interest. Wiggins and O'Hare $(1995,2003)$ have shown that the specific features acquired about weather-related phenomena are helpful to pilots in their ability to not only understand but anticipate what these features tell them about the current weather conditions. Knecht (2008a, b) has come to a similar conclusion, suggesting that the specific types of weather event faced (e.g., storms, ice) have a large impact on the types of decision-making responses the pilots make and how they use such weather-related information.

Knowing that something presents a risk is an important information processing capability, but so too is being able to perceive something as risky or not risky and acting on that perception. This becomes critical during flight situations that rapidly become hazardous (You et al, 2013), such as changing or unexpected weather situations. Risk perception then requires an adequate appraisal of the situation, how to adequately address the situation, and act accordingly. Misperception of risk (over- or under-estimation) can and does lead to flight accidents (Hunter, 2002).

It is also been shown that the perception of weather radar data (Wiggins, 2014) presents potential problem areas, even for experienced pilots. Wiggins (2014) recruited 61 pilots and had 
them rate the level of turbulence across 11 standard weather radar displays. They were also asked their confidence levels in continuing to fly 80 nautical miles. Results revealed not only a need for better design in weather radar systems, but also better and more adequate training of pilots with regard to how they interpret weather radar displays and returns. This suggests that even experienced pilots have issues with weather-related information. Wiggins (2014) further suggests that the development of certain cognitive competencies is critical for weather radar interpretation. Likewise, the development of risk perception with regard to weather-related information is also critical. Analyzing risk perception in student aviation students and nonaviation students is a step in this direction.

\section{The Current Study}

The current research used the Risk Perception Scale (Hunter, 2002, 2006) to compare ratings of risk by student participants with no aviation experience (control group)to ratings by student participants with aviation experience (experimental group) on four measures of risk perception, three of which pertained specifically to flight situations (P2Fly, P2Base, P2Wx) and one that did not (P2Life). We expected that the participants with aviation experience would perceive higher risk than those participants with no aviation experience across the three measures of risk perception related to aviation (P2Fly, P2Base, P2WX). Likewise, we expected no group differences on the risk perception measure not related to aviation (P2Life). Finally, in our aviation subjects we expect a negative relationship to exist between risk perception and aviation experience.

\section{Methods}

Participants. A total of 134 undergraduates $(M$ age $=22$ years, $M$ years of education $=$ 15) from a large Midwestern university participated (63 aviation students, 71 non-aviation students). They all responded to advertisements posted on campus for this study. The aviation students averaged 299 hours of flight time, 78 hours as a pilot in command on cross country flights, averaged 37 hours of actual instrument flight and averaged 28 hours of simulated instrument flight. This data was obtained via self-report and is defined here as aviation experience.

Measures \& Procedures. The Risk Perception Scale (RPS; Hunter, 2002; 2006) was used. This instrument contains 261 -sentence statements that are rated on a 0 (no risk) to 100 (high risk) scale. The questions are answered as if the action is to be performed tomorrow. Example items for each composite score include Composite Risk - Non Aviation (P2Life) "Jaywalk (cross in the middle of the block) across a busy downtown street.", Composite Risk Aviation (P2FLY): "Start a light aircraft with a dead battery by hand-propping it.", Baseline Risk - Flying (P2Base): "During the daytime, take a cross-country flight in which you land with over an hour of fuel remaining.", and Weather Risk Rating Score (P2Wx): "Fly in clear air at 6,500 feet between two thunderstorms about 25 miles apart."

Participants were tested individually. After reading and signing a consent form, they completed a background information questionnaire (which asked about age and education level). Aviation students answered these questions as well as questions about total hours of flight time, total hours as a pilot in command on cross-country flights, total hours of actual instrument flight 
and total hours of simulated instrument flight. Participants then filled out the RPS. The entire experiment took approximately 30 minutes to complete.

\section{Results}

A between-groups $t$-test was used with alpha set at $p=.05$. Aviation students and nonaviation students did not differ on age or education. Risk Perception Scale data and results are in Table 1. Also, in our aviation students we did observe a negative relationship (albeit nonsignificant) between weather risk perception scores and hours of actual instrument flight $[(r$ $(132)=-.07, p=.28)]$ and simulated $[(r(132)=-.11, p=.19)]$ instrument flight, suggesting that weather risk perception decreases with more hours of actual and simulated flight (i.e., aviation experience).

\section{Discussion}

Aviation students and non-aviation students completed the Risk Perception Scale in an effort to see how aviation experience (defined as total hours of flight time, total hours of being a plot in command on cross country flights and total hours of simulated and actual instrument flight) impacted risk perception in student aviation and non-aviation students. In support of our predictions, participants experienced in aviation (aviation students) perceived significantly more risk for risk related to weather conditions, based on P2Wx measures.

Contrary to our predictions, however, was the fact that the non-aviation students perceived more risk than aviation students in measures of non-aviation composition risk (P2Life), baseline aviation risk (P2Base) and composite aviation risk (P2Fly). We had expected those experienced in aviation to display more risk perception for P2Fly and P2Base. Nonaviation students also registered their highest risk perception for the weather risk questions, which follows if one perceives adverse weather conditions to be risky for flying, even if not experienced with flying. Also, non-aviation students may not have a clear idea what kind of risks are involved in aviation and perceive them as risky in general. The higher score on the weather risk questions from aviation students, however, suggests that these individuals take weather risk more seriously, especially since weather-related accidents occur frequently (Goh \& Wiegmann, 2002) and since these are pilots in training who want to minimize such types of accidents in the future. Aviation students may also know the risks involved in aviation in greater detail and may also get them from first-hand experience. Finally, like the non-aviation participants, the weather risk score for those experienced with aviation was higher than any of the other three risk scores, suggesting weather is considered risky for flight situations regardless of whether or not one has flight or aviation experience (Goh \& Weigmann, 2002).

Our research has some shortcomings that need to be discussed. First, while all participants were college students we did test those majoring in aviation who had flying experience. Testing non-students and older pilots would add to our results (Guohua, Baker, Grabowski, Qjang, McCarthy \& Rebok, 2003; Hardy \& Parasuraman, 1997). Second, the estimates of flying experience were made via self-report. Third, other measures of risk perception would have added to the results, and extended them beyond the RPS. Fourth, the sample was not totally random, as participants volunteered based on flyers posted on campus. Future studies could address this with a better sampling technique. 


\section{Conclusion}

To summarize, we have shown that weather risk (as measured by the RPS) is a concern to aviation students. The trend that this risk perception declines with actual and simulated flight hours (defined here as aviation experience) suggests that weather risk perception should continue to be an integral part of aviation training programs. Future studies should continue to examine factors that impact aviation students risk perception and how that perception can be translated into good flying practice. 


\section{References}

Burian, B., Barshi, I., \& Dismukes, K. (2006). The challenge of emergency and abnormal situations. NASA Technical Memorandum 2005-213462. Moffett Field, CA: NASA Ames Research Center.

Goh, J., \& Wiegmann, D. (2001, October). An investigation of the factors that contribute to pilots' decisions to continue Fisual Flight Rules Flight into adverse weather. In Proceedings of the Human Factors and Ergonomics Society Annual Meeting (Vol. 45, No. 2, pp. 26-29). SAGE Publications.

Goh, J. \& Wiegmann, D. (2002). Human factors analysis of accidents involving visual flight rules flight into adverse weather. Aviation, Space, and Environmental Medicine, 73(8),817-822.

Green, M. F. (2001). Aviation system safety and pilot risk perception: Implications for enhancing decision-making skills. Journal of Air Transportation World Wide, 6, 98-111.

Hunter, D. R. (2002). Risk perception and risk tolerance in aircraft pilots (No. DOT/FAA/AM 02/17). Washington, DC: Federal Aviation Administration Office of Aviation Medicine.

Hunter, D.R. (2006). Risk perception among general aviation pilots. International Journal of Aviation Psychology, 16, 135-144. doi: http://dx.doi.org/10.1207/s15327108ijap1602_1

Knecht, W. R. (2008a). Use of weather information by general aviation pilots. Part 1. Quantitative: Reported use and value of providers and products. Tech Report PB2008 108836, FAA, Oklahoma City, OK. Civil Aerospace Medical Institute.

Knecht, W. R. (2008b). Use of weather information by general aviation pilots. Part 2. Quantitative: Exploring factors involved in weather-related decision-making. Tech Report PB2008-108837, FAA, Oklahoma City, OK. Civil Aerospace Medical Institute.

Slovic, P., \& Lichtenstein, S. (1968). Relative importance of probabilities and pay offs in risk taking. Journal of Experimental Psychology Monograph, 78, 3, Pt. 2. doi: http://dx.doi.org/10.1037/h0026468

Tversky, A., \& Kahneman, D. (1981). The framing of decisions and the psychology of choice. Science, 211, 453-458. doi: http://dx.doi.org/10.1126/science.7455683

You, X., Ji, M., \& Han, H. (2013). The effects of risk perception and flight experience on airline pilots' locus of control with regard to safety operation behaviors. Accident Analysis and Prevention, 57, 131-139. doi: http://dx.doi.org/10.1016/j.aap.2013.03.036

Wiggins, M.W. (2014). Differences in situation assessments and prospective diagnoses of simulated weather radar returns amongst experienced pilots. International Journal of Industrial Ergonomics, 44, 18-23. doi: http://dx.doi.org/10.1016/j.ergon.2013.08.006 
Wiggins, M.W., \& O'Hare, D. (1995). Expertise in aeronautical weather-related decision making: A cross sectional analysis of general aviation pilots. Journal of Experimental Psychology: Applied, 1, 305-320. doi: http://dx.doi.org/10.1037/1076-898X.1.4.305

Wiggins, M.W., \& O'Hare, D. (2003). Weatherwise: Evaluation of a cue-based training approach for the recognition of deteriorating weather conditions. Human Factors, 45, 337-345. doi: http://dx.doi.org/10.1518/hfes.45.2.337.27246 
Table 1

Mean (and standard deviation) values for demographic, and RPS data and statistical results as a function of group membership

\begin{tabular}{lcccc} 
Measure & Aviation Students & Non-Aviation Students & $t(133)$ & $p$ \\
\hline Age-years & $22.36(4.40)$ & $22.29(4.02)$ & .10 & .93 \\
Education (years) & $15.02(1.08)$ & $15.05(1.18)$ & .14 & .88 \\
P2Life & $22.47(14.08)$ & $31.59(18.26)$ & 3.21 & .01 \\
P2Fly & $31.50(12.65)$ & $37.54(21.28)$ & 1.96 & .052 \\
P2Base & $12.65(12.16)$ & $25.82(26.81)$ & 3.59 & .01 \\
P2Wx & $53.95(20.14)$ & $45.72(23.87)$ & 2.15 & .034 \\
\hline
\end{tabular}

Note: P2Life indicates Composite Risk-Non Aviation; P2Fly indicates Composite RiskAviation; P2Base indicates Baseline Risk; P2Wx indicates Weather Risk Rating Score. 